\title{
Moving Well-Being Well: Investigating the maturation of fundamental movement skill proficiency across sex in Irish children aged five to
}

\section{twelve}

Stephen Behan ${ }^{\mathrm{a}, \mathrm{b} *}$, Dr Sarahjane Belton ${ }^{\mathrm{a}}$, Cameron Peers ${ }^{\mathrm{a}, \mathrm{b}}$, Prof Noel E. O'Connor ${ }^{\mathrm{b}}$, and Dr Johann Issartel ${ }^{\mathrm{a}}$.

${ }^{a}$ School of Health and Human Performance, Dublin City University, Dublin, Ireland;

${ }^{b}$ Insight Centre for Data Analytics, Dublin City University, Dublin, Ireland.

Author Details

Stephen Behan* (Corresponding author): School of Health \& Human Performance, DCU email: stephen.behan@dcu.ie

Phone: +353 864062452

Twitter: @behan_s

ORCiD: https://orcid.org/0000-0003-3085-2792

Sarahjane Belton: School of Health \& Human Performance, DCU

email: sarahjane.belton@dcu.ie

twitter:@sjbelton

ORCiD: https://orcid.org/0000-0001-9672-6276

Cameron Peers: School of Health and Human Performance, DCU

email: cameron.peers2@mail.dcu.ie

twitter:@cameronpeers

Noel E. O'Connor: Insight Centre for Data Analytics, DCU

email: noel.oconnor@dcu.ie

twitter:@oconnorn

ORCiD: https://orcid.org/0000-0002-4033-9135

Johann Issartel: School of Health \& Human Performance, DCU

email: johann.issartel@dcu.ie

twitter:@johann80johann

ORCiD: https://orcid.org/0000-0003-1016-1409

This publication has emanated from research supported in part by a research grant from Science Foundation Ireland (SFI) under Grant Number SFI/12/RC/2289, co-funded by the European Regional Development Fund, with assistance from the GAA's Research and Games Development department and Dublin GAA. 


\section{Moving Well-Being Well: Investigating the maturation of fundamental movement skill proficiency across sex in Irish children aged five to}

\section{twelve}

Fundamental movement skills (FMS) are the basic building blocks of more advanced, complex movements required to participate in physical activity. This study examined FMS proficiency across the full range of Irish primary school children ( $\mathrm{n}=2098$, 47\% girls, age range 5-12 years). Participants were assessed using the Test of Gross Motor Development, $3^{\text {rd }}$ edition (TGMD-3), Victorian Fundamental Movement skills manual, and the balance subtest from the Bruininks-Oseretsky Test of Motor Proficiency 2 (BOT-2). Independent sample t-tests and a one way between groups ANOVA with planned comparisons were used analyse sex and age differences. Mastery or near mastery of skills ranged from $16 \%$ for overhand throw, to $75.3 \%$ for run. Girls scored significantly higher than boys in the locomotor and balance subtests with the boys outperforming the girls in object control skills. Improvements in ability can be seen over time $(\mathrm{F}(8,1968)=70.18, \mathrm{p}<0.001)$, with significant increases in FMS proficiency seen up to the age of ten, after which proficiency begins to decline. The findings demonstrate the low levels of FMS proficiency amongst Irish primary school children, the differences between sex that exist, and highlights the need for more programmes that focus on developing these FMS at an early age.

Keywords: Fundamental movement skills; FMS; TGMD-3; motor competence; motor development; physical activity. 


\section{Introduction}

The benefits of participation in regular physical activity (PA) are well documented (Warburton et al., 2006). A report by the American Physical Activity Guidelines Advisory Committee (2018) states physically active children have reduced risks of excessive increases in body weight, cardiovascular disease, osteoporosis, and type 2 diabetes, as well psychological and emotional benefits such as increased mental health, higher self-esteem and better emotional self-efficacy (Eime et al., 2013). The current guidelines state that children and adolescents should engage in at least one hour of moderate to vigorous physical activity (MVPA) each day, yet research from around the world suggests that children and adolescents typically fall well below this target (Cavalheri et al., 2016; Colley et al., 2017; Katzmarzyk \& Staiano, 2017). In Ireland alone, the Children's Sport Participation and Physical Activity (CSPPA) study found just $14 \%$ of Irish adolescents engage in the recommended one hour per day of moderate to vigorous activity (Woods et al., 2010). It is therefore important to identify factors that influence PA participation to increase physical activity levels in children and youths; one of them being their motor skill proficiency level.

Fundamental movement skills (FMS) are purported to have a significant impact in PA participation, with increased proficiency associated with increased PA in adolescents (Robinson et al., 2015). FMS are the building blocks of more advanced, complex movements required to participate in to participate in games, sports or other context specific physical activity (Logan et al., 2018). The three domains of FMS are: locomotor skills (running and jumping, etc.), object control skills (throwing and kicking, etc.), and stability skills (i.e. balance) (Gallahue \& Ozmun, 2006). Once refined and combined, these FMS support the acquisition of sports specific complex movement skills (Metcalfe \& Clark, 2002). A lack of proficiency would in turn have consequences in terms 
of reduced levels of PA participation (Jaakkola et al., 2016). The literature supports this evidence: FMS proficiency has shown positive associations with increased physical activity in both children (Barnett et al., 2009; Cliff et al., 2009; Robinson et al., 2015) and adolescents (Barnett et al., 2009; Lubans et al., 2010; Okely et al., 2001), with Stodden (2012) maintaining that early mastery of FMS can lead to a more active lifestyle over a lifetime.

Research indicates that early childhood is a critical period for FMS development (Barela, 2013; Hardy et al., 2013). Clark (2007) illustrates that FMS must be developed through practice. In addition, girls and boys do not typically progress to mastery level at the same rate (Cliff et al., 2009). Research suggests differences in FMS proficiency between sex in children of the same age, with girls displaying higher proficiency in locomotor and stability skills, and boys achieving higher scores in object control skills (Barnett et al., 2009; Erwin \& Castelli, 2008; Goodway et al., 2013; Hardy et al., 2010). Gallahue and Ozmun (2006) report that children have the potential to master most of the FMS by the age of six, in contrast, Australian researchers suggest mastery can be achieved between nine and ten years of age (Hardy et al., 2010). It is therefore alarming to see a worldwide trend, with Australia (van Beurden et al., 2002), Singapore (Mukherjee et al., 2017) and Canada (LeGear et al., 2012), among countries failing to exhibit age appropriate FMS proficiency. O' Brien et al. (2016) measured FMS in Irish adolescents and found that only $11 \%$ could adequately perform the required movement patterns. This is concerning considering that these adolescents should have completed eight years of primary school physical education, in which these basic movement skills are targeted throughout the curriculum (Irish Primary PE Curriculum, Department of Education and Science, 1999).

The adolescent motor skill proficiency levels are well documented (Belton et al., 
2014; O' Brien et al., 2016), but we still miss an overall picture of the proficiency level, and the rate of development, during the eight years of primary school. This study aims to, 1) Report nationwide FMS proficiency levels, 2) Explore the effect of maturation, and 3) Examine potential disparities between the sexes in FMS, across the age span of Irish primary school children. 


\section{Methodology}

\section{Participants}

Cross-sectional data were collected as part of a national physical literacy study 'Moving Well-Being Well'. Over 50 schools were approached with 44 agreeing to take part. Participants ( $\mathrm{n}=2098,47 \%$ girls, ranging from 5-12 years of age, mean age $9.2 \pm 2.04$ ) were then recruited from these 44 schools across twelve counties (56\% rural, $44 \%$ urban), encompassing all four provinces in Ireland and Northern Ireland. Irish primary schools in areas classed as 'socioeconomically disadvantaged' qualify for the Delivering Equality of Opportunity in Schools (DEIS) programme, and comprise $19.7 \%$ of primary schools in Ireland (Junior et al., 2005). This study's sample includes 18.8\% DEIS schools. Data were collected March through June 2017 across the full range of the primary school cycle, typically developing junior infants to sixth class. The subjects were classified per age and sex for data analysis.

Ethical approval was obtained from the institutional Research Ethics Committee (DCU/REC/2017/029). The principals of each of the participating schools initially consented to participation, while parental consent and participant assent were also obtained. An age appropriate child assent form was supplied to participants in the younger classes (junior infants to $2^{\text {nd }}$ class, 5- 8 years of age). Participants were assigned a unique numerical code to ensure their anonymity was maintained, with age and sex collected through the consent forms and questionnaires administered in the classroom.

\section{Measures}

FMS proficiency was measured using the Test of Gross Motor Development-3rd Edition (TGMD-3). The TGMD-3 is comprised of locomotor (run, skip, gallop, slide, hop, and horizontal jump) and object-control (catch, overhand throw, underhand roll, kick, two 
handed strike, one handed strike, and stationary dribble) skill subtests (Ulrich, 2013). An additional locomotor skill test was included, the vertical jump, from the Victorian Fundamental Motor Skills manual (Department of Education Victoria, 1996, Fundamental Motor Skills: A Manual for Classroom Teachers, Melbourne: Education Department of Victoria). Both have been used in previous research and have a high degree of validity and reliability (Cools et al., 2009; Fundamental Motor Skills: A Manual for Classroom Teachers, 1996). The TGMD-3 and the vertical jump test assess the performance of skill components, rather than the outcome or product of performance, and again have established validity (Temple \& Foley, 2017) and reliability $(\alpha=0.81)$ in this age cohort (Cools et al., 2009; Yee, Wong, \& Cheung, 2010).

While the TGMD is a common assessment tool used in many studies worldwide, some would criticise the lack of a stability component (Rudd et al., 2015). To this end, a subtest of the Bruininks-Oseretsky Test of Motor Proficiency 2 (BOT-2) Short Form was utilised to assess the participants' balance. The BOT-2 Short Form is a motor competence battery originally designed to identify individuals with mild to severe motor problems (Fransen et al., 2014). It has been widely used in previous research (Cools et al., 2009), and has proven validity (Fransen et al., 2014) and reliability $(\alpha=0.92)$ (Crosetto et al., 2009; Fransen et al., 2014). The balance assessment consists of two tasks, walking forward along a straight line, and standing on one leg on a balance beam with eyes open. In contrast to the TGMD-3, these tests are based on the outcome of the performance, and participants are awarded points on a scale from zero to four for each task (Deitz et al., 2009). While the preference would have been to use a process -based stability assessment for consistency purposes, the authors deemed that there were no existing and valid process-based stability assessment suitable for use in this study. 


\section{Data Collection}

All research team members were required to undergo formal training in order to ensure thorough understanding of the skill assessment process as well as consistency in assessing the test subjects. In order to ensure consistent and high quality data, the team were required to meet a $95 \%$ inter-observer agreement on a pre-coded data set. This data set was pre-coded by the lead researcher and the research team members were blind to the conditions of coding.

Prior to assessment, a visual demonstration of the skill was performed by a trained member of the research team, consistent with the protocol defined by Ulrich (2013), and widely used throughout the literature (Cools et al., 2009; Ulrich, 2013). There were no verbal feedback or cues and participants were unaware of the specific components being measured. Participants were each asked to perform every skill twice, after first completing a practice trial to familiarise themselves with the skill. A trained member of the research team observed each trial and assessed each skill component. The number of skill criteria varies from three to six across the various skills. A score of one was noted if the participant fulfilled the necessary criteria, and a zero indicates that they failed to meet these criteria. The scores from both trials were totalled and this indicates the participants raw score per skill. Upon completion of all skill assessments, the locomotor and object control skills were totalled to give raw subtest scores, before being combined to give an overall raw FMS score.

The first balance subtest, walking forward on a straight line, is graded based on the amount of steps a participant takes while adhering to strict criteria (Bruininks, 2005). Points were awarded to the participant in line with the number of steps taken, e.g. six continuous steps equals four points. Standing on one leg on the balance beam was scored 
based on the time a child could maintain their balance while adhering to the prescribed criteria (Bruininks, 2005). Again, points were awarded based on the time a participant kept their balance, e.g. over ten seconds equals four points. If a participant scored maximum points in the first trial, there was no need to complete a second trial.

Traditionally, the process orientated FMS assessments are measured by using the pen and paper method (Ulrich, 2013; Yun \& Ulrich, 2002). A similar pen and paper method has been used in the past for the balance test (Bruininks, 2005). All scores must then be input into a database before any statistical analyses can be undertaken. These methods are time consuming as well as doubling the opportunity for human error to occur during data entry. To counteract this, a unique iPad application was developed to collect the data. The equivalent of the paper version was created in the iPad application. This app allowed the research team to assess the participants through their unique numerical code using electronic tablets. Throughout the process based assessments, the assessor clicked a skill component box on the touchscreen if the skill criteria was fulfilled, and left the box blank if not. All checked boxes were recorded as a one and unchecked boxes as a zero. The balance test was also recorded on the app, with a checkbox system for walking forward on a straight line, and an inbuilt timer for the balance beam assessment. The protocols for each assessment were followed at all times (Bruininks, 2005; Ulrich, 2013). When connected to a secure network, the tablet uploaded the complete data set to a secure server based on the university campus. The app can be used by multiple users at a time and allows for a secure cloud based upload of pseudo-anonymised data. This database can be downloaded then provides secure access for analyses, without the need for manual data entry. The system has been approved by the University's Ethics committee and is also compliant with the new European general data protection regulations (GDPR). 


\section{Data Analysis}

All data were analysed using SPSS version 24. Descriptive statistics and frequency tables were produced to determine the percentage of participants who had achieved mastery or near mastery in each skill. 'Mastery' of the process oriented locomotor and object control skills is the correct performance of all the skill components associated with each skill over both the trials. 'Near Mastery' is when an individual performs all but one of the components correctly over both trials (van Beurden et al., 2002). Any participant who did not fulfil the criteria to achieve mastery or near mastery status was classified as poor (Booth et al., 1999). Mastery for the product based balance assessment is classified as scoring the maximum score of four in each of the assessments to give a total of eight points (Bruininks, 2005). Using the above techniques, the raw scores for each skill were categorised into an additional variable and coded as mastery/near mastery (MNM), or poor (Okely \& Booth, 2004). Frequencies were calculated to report a MNM percentage for each individual skill.

A commonly held hypothesis is that FMS proficiency improves through maturation (Goodway et al., 2013). In order to examine this hypothesis, a one-way between-groups ANOVA with planned comparisons was used to explore the impact of age on overall FMS, locomotor, object control, and balance skills. Statistical significance was set at $p<0.05$. Participants were grouped by age and comparisons were planned to compare each age group to the next in chronological order. Effect size is reported using eta squared, which classifies 0.01 as a small effect, 0.06 as a medium effect and 0.14 as a large effect (Cohen, 1988).

Individual skills were categorised by age and independent sample t-tests were used to analyse differences between sex in the locomotor, object control and balance 
subtest scores, as well as the overall FMS totals. The vertical jump was added to the locomotor subset. The overall FMS score is made up of the raw scores of the locomotor, object control and balance subtests. 


\section{Results}

Only participants who returned completed parental consent and assent forms $(n=2098$, $47 \%$ girls) were eligible for inclusion in the study. The sample consisted of Irish primary school children, participants ranging in age from five to 12 . The overall FMS score (Figure 1) was calculated only for those who had complete data for all three subsets ( $n=1968$ participants, $47.2 \%$ girls). Similarly, only participants who were assessed in all components of the locomotor $(n=1979,46.9 \%$ girls $)$, object control $(n=2024,46.7 \%$ girls), and balance tests ( $\mathrm{n}=2038,46.9 \%$ girls), were included in the subset samples. When examining MNM in individual skills (Figure 1), the skill that demonstrated the highest percentage of proficiency was run at $75.3 \% \mathrm{MNM}$, with the poorest performed skill being the overhand throw, which achieved just 16\% MNM.



Figure 1. Percentage of Mastery/Near Mastery for locomotor and object control 
A more comprehensive look at the MNM across the school age span can be seen in Table 1, which shows a breakdown of MNM by age category for each individual skill, as well as the overall FMS and the; locomotor, object control and balance subsets.

Table 1. Percentage of mastery/near mastery across the age-span of school going children

\begin{tabular}{l|llllllll}
\multicolumn{1}{c|}{} & \multicolumn{10}{c}{ AGE } \\
\hline & $\mathbf{5}$ & $\mathbf{6}$ & $\mathbf{7}$ & $\mathbf{8}$ & $\mathbf{9}$ & $\mathbf{1 0}$ & $\mathbf{1 1}$ & $\mathbf{1 2}$ \\
RUN & $\mathbf{n = 1 1 7}$ & $\mathbf{n = 2 5 0}$ & $\mathbf{n = 3 1 8}$ & $\mathbf{n = 3 0 2}$ & $\mathbf{n = 3 6 0}$ & $\mathbf{n = 2 7 7}$ & $\mathbf{n = 2 7 0}$ & $\mathbf{n = 1 7 5}$ \\
SKIP & 73.5 & 69 & 77.5 & 78.3 & 73.5 & 81.3 & 77.2 & 67.8 \\
GALLOP & 30.8 & 32.3 & 40.3 & 47.8 & 52.7 & 57.9 & 59.6 & 59.1 \\
SLIDE & 6.0 & 10.0 & 12.0 & 21.6 & 22.5 & 26.7 & 28.5 & 22.7 \\
HOP & 31.6 & 57.3 & 57.1 & 67.7 & 81.7 & 78.0 & 65.2 & 73.3 \\
HORIZONTAL JUMP & 46.2 & 58.4 & 60.8 & 69.2 & 68.2 & 78.1 & 82.2 & 76.2 \\
VERTICAL JUMP & 29.1 & 31.4 & 44.4 & 41.2 & 50.1 & 53.8 & 52.1 & 65.7 \\
CATCH & 9.4 & 15.9 & 26.3 & 35.2 & 36.9 & 42.1 & 46.6 & 45.9 \\
OVERHAND THROW & 41.9 & 54.0 & 62.9 & 76.9 & 81.1 & 85.0 & 83.8 & 85.5 \\
UNDERHAND ROLL & 5.1 & 4.8 & 13.0 & 14.6 & 12.4 & 21.6 & 26.9 & 26.7 \\
KICK & 12.1 & 23.4 & 28.2 & 35.5 & 37.0 & 46.3 & 53.9 & 55.8 \\
TWO HANDED STRIKE & 29.1 & 30.9 & 37.3 & 46.8 & 49.6 & 61.9 & 67.9 & 69.8 \\
ONE HANDED STRIKE & 20.5 & 23.7 & 29.4 & 25.9 & 28.2 & 38.1 & 41.0 & 31.2 \\
STATIONARY DRIBBLE & 8.5 & 13.3 & 16.2 & 21.7 & 27.6 & 41.3 & 48.7 & 45.7 \\
TOTAL BALANCE & 8.5 & 27.6 & 35.6 & 51.2 & 68.7 & 68.1 & 63.5 & 68.8 \\
TOTAL LOCOMOTOR & 10.3 & 23.2 & 27.4 & 40.4 & 54.4 & 64.3 & 59.6 & 60.6 \\
TOTAL OBJECT CONTROL & 29.0 & 35.0 & 40.7 & 46.1 & 49.3 & 53.5 & 52.8 & 52.8 \\
TOTAL FMS & 18.0 & 25.4 & 31.8 & 38.9 & 43.5 & 51.8 & 55.1 & 54.8 \\
& 25.2 & 32.3 & 38.6 & 45.3 & 49.3 & 55.7 & 56.9 & 56.7
\end{tabular}

A one-way between-groups ANOVA with planned comparisons was used to explore the impact of age on overall FMS, locomotor, object control, and balance skills (Figure 2). There was a statistically significant difference at the $p<0.05$ level in overall FMS scores, $(F(7,1950)=103.72, p<0.001)$, with a large effect size calculated using eta squared of 0.27 . Similarly, there was a statistically significant difference in the locomotor skill scores, $(\mathrm{F}(7,1964)=51.47, \mathrm{p}<0.001)$, with a large effect size of 0.16 . There was also a statistically significant difference in the object control skills, $(F(7,2011)=101.15, p<0.001)$, with a 
large effect size of 0.26 . Lastly, there was a statistically significant difference in the balance skill scores, $(\mathrm{F}(7,2039)=31.88, \mathrm{p}<0.001)$, with a moderate effect size of 0.10 .



Figure 2. Percentage change between age groups of raw scores for locomotor, object control, balance, and overall FMS scores. Significant differences between ages noted with an asterix, $p<0.05=*, p<0.01=* *, P<0.001=* * *$.

The planned comparisons compare each age group to the one above it, for example five years of age to six years of age. In overall FMS scores there is a significant difference between five and six years of age $(F(1,255.9)=18.84, p<0.001)$. There are also significant differences between; six and seven years of age $(F(1,549.9)=6.08, p=0.014)$, seven and eight years of age $(F(1,591.5)=21.91, p<0.001)$, eight and nine years of age $(F(1,567.6)=14.71, p<0.001)$, and nine and ten years of age $(F(1,535.4)=24.09 .77$, $\mathrm{p}<0.001)$. These findings are reflected in the three subtests, with the exception of locomotor $(\mathrm{F}(1,541.9)=2.41, \mathrm{p}=0.121)$ and balance $(\mathrm{F}(1,552.4)=0.02, \mathrm{p}=0.882)$ reporting no significant change between the ages of six and seven. Object control was the only subtest to report any significant difference between 10 and 11 years of age 
$(\mathrm{F}(1,519.9)=2.61, \mathrm{p}=0.001)$. There are no significant changes between 11 and 12 years of age in any of the above and results are detailed in Figure 2.

Independent sample t-tests were conducted to compare overall FMS scores for boys and girls across the Irish primary school years (Table 2). The same methods were used to compare the three subtest scores; locomotor skills (Table 3), object control skills (Table 4) and balance skills (Table 5), for boys and girls.

Table 2. Mean ( $\pm S D)$ of overall FMS scores across age and sex

\begin{tabular}{c|rrr|rrr|cccc}
\multicolumn{4}{c}{ BOYS } & \multicolumn{3}{c}{ GIRLS } & \multicolumn{1}{c}{ SIG } & CI & EFFECT & DIFF \\
\hline AGE & \multicolumn{1}{|c}{$\mathbf{N}$} & Mean & $\mathbf{\pm S D}$ & $\mathbf{N}$ & Mean & $\mathbf{\pm S D}$ & $\mathbf{P}$ & $\mathbf{9 5 \%}$ & Eta $^{2}$ & \% \\
$\mathbf{5}$ & 63 & 65.3 & 14.7 & 52 & 69.5 & 12.0 & 0.099 & $-9.23,0.8$ & 0.02 & $6.5 \%$ \\
$\mathbf{6}$ & 137 & 75.2 & 16.1 & 105 & 73.0 & 15.3 & 0.283 & $-1.83,6.22$ & 0.00 & $3.0 \%$ \\
$\mathbf{7}$ & 167 & 78.9 & 21.7 & 143 & 77.0 & 18.4 & 0.416 & $-2.63,6.33$ & 0.00 & $2.4 \%$ \\
$\mathbf{8}$ & 149 & 84.6 & 18.8 & 145 & 85.6 & 14.5 & 0.618 & $-4.82,2.87$ & 0.00 & $1.2 \%$ \\
$\mathbf{9}$ & 159 & 89.7 & 15.5 & 172 & 89.9 & 12.0 & 0.908 & $-3.19,2.84$ & 0.00 & $0.2 \%$ \\
$\mathbf{1 0}$ & 129 & 96.5 & 15.4 & 116 & 94.2 & 10.4 & 0.163 & $-0.95,5.61$ & 0.01 & $2.5 \%$ \\
$\mathbf{1 1}$ & 136 & 98.7 & 11.7 & 116 & 95.5 & 10.5 & $0.025^{*}$ & $0.4,5.95$ & 0.02 & $3.3 \%$ \\
$\mathbf{1 2}$ & 93 & 98.9 & 12.9 & 76 & 93.4 & 13.9 & $0.009 * *$ & $1.38,9.52$ & 0.04 & $5.8 \%$
\end{tabular}

Table 3. Mean ( $\pm S D)$ of locomotor skills scores across age and sex

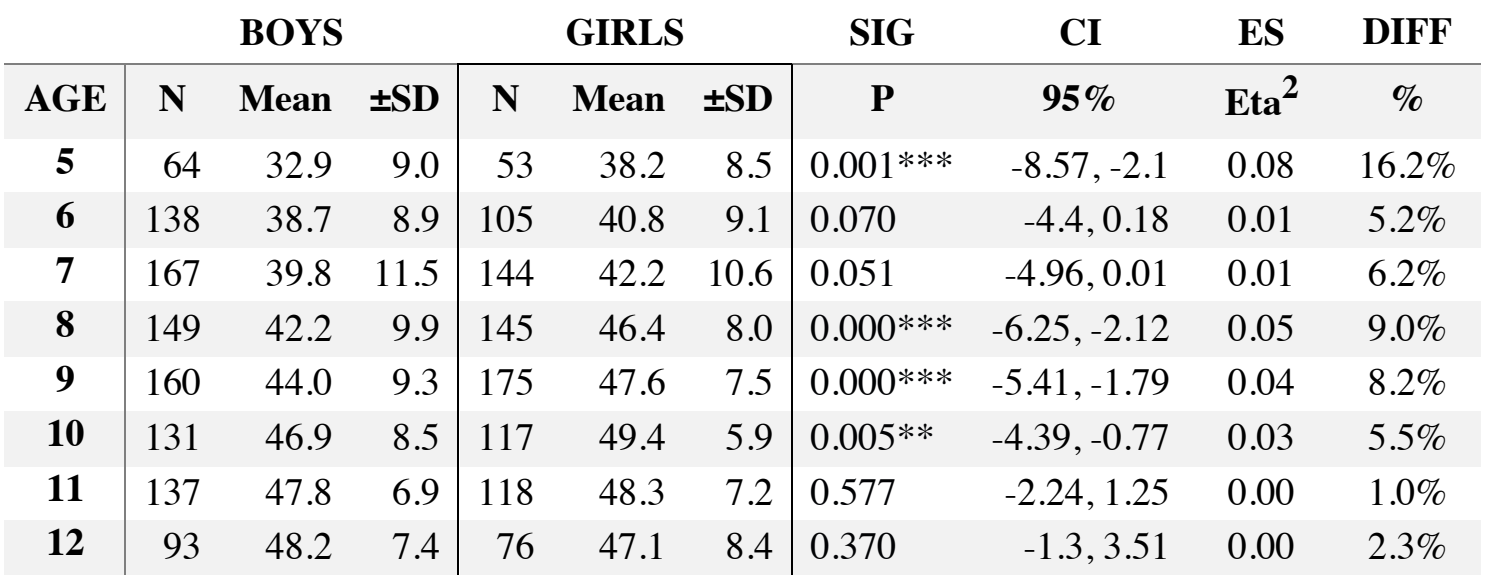


Table 4. Mean $( \pm S D)$ of object control skills scores across age and sex

\begin{tabular}{|c|c|c|c|c|c|c|c|c|c|c|}
\hline \multicolumn{5}{|c|}{ BOYS } & \multicolumn{2}{|c|}{ GIRLS } & SIG & \multirow{2}{*}{$\begin{array}{c}\text { CI } \\
95 \% \mathrm{CI}\end{array}$} & \multirow{2}{*}{$\begin{array}{c}\text { ES } \\
\text { Eta }^{2}\end{array}$} & \multirow{2}{*}{$\begin{array}{c}\text { DIFF } \\
\%\end{array}$} \\
\hline AGE & $\mathbf{N}$ & Mean & $\pm \mathrm{SD}$ & $\mathbf{N}$ & Mean & \pm SD & $\mathbf{P}$ & & & \\
\hline 5 & 63 & 28.0 & 7.3 & 52 & 25.3 & 7.6 & 0.056 & $-0.07,5.43$ & 0.03 & $10.6 \%$ \\
\hline 6 & 137 & 31.4 & 9.0 & 107 & 26.3 & 7.9 & $0.000 * * *$ & $2.92,7.26$ & 0.08 & $19.3 \%$ \\
\hline 7 & 169 & 33.5 & 10.5 & 143 & 29.3 & 8.4 & $0.000 * * *$ & $2.07,6.28$ & 0.05 & $14.3 \%$ \\
\hline 8 & 151 & 36.1 & 10.7 & 146 & 32.4 & 8.2 & $0.001 * * *$ & $1.57,5.92$ & 0.04 & $11.6 \%$ \\
\hline 9 & 172 & 39.1 & 7.9 & 177 & 35.3 & 6.6 & $0.000 * * *$ & $2.26,5.31$ & 0.06 & $10.7 \%$ \\
\hline 10 & 141 & 42.3 & 7.7 & 128 & 37.3 & 6.8 & $0.000 * * *$ & $3.19,6.7$ & 0.10 & $13.2 \%$ \\
\hline 11 & 145 & 43.9 & 6.2 & 118 & 39.9 & 6.3 & $0.000 * * *$ & $2.48,5.53$ & 0.09 & $10.0 \%$ \\
\hline 12 & 94 & 44.1 & 5.9 & 76 & 39.3 & 6.6 & $0.000 * * *$ & $2.91,6.69$ & 0.13 & $12.2 \%$ \\
\hline
\end{tabular}

Table 5. Mean ( $\pm S D)$ of balance skills scores across age and sex

\begin{tabular}{c|rrr|rrr|crcc}
\multicolumn{4}{c}{ BOYS } & \multicolumn{3}{c}{ GIRLS } & \multicolumn{1}{c}{ SIG } & CI & ES & DIFF \\
\hline $\mathbf{A G E}$ & $\mathbf{N}$ & Mean & $\mathbf{\pm}$ SD & $\mathbf{N}$ & Mean & $\mathbf{\pm S D}$ & $\mathbf{P}$ & $\mathbf{9 5 \%} \mathbf{C I}$ & $\mathbf{E t a}^{2}$ & $\mathbf{\%}$ \\
$\mathbf{5}$ & 64 & 4.5 & 2.1 & 53 & 5.2 & 2.0 & $0.039 *$ & $-1.55,-0.04$ & 0.04 & $17.8 \%$ \\
$\mathbf{6}$ & 138 & 5.2 & 2.0 & 107 & 5.9 & 2.0 & $0.022^{*}$ & $-1.12,-0.09$ & 0.02 & $11.5 \%$ \\
$\mathbf{7}$ & 170 & 5.5 & 2.5 & 146 & 5.6 & 2.3 & 0.689 & $-0.64,0.42$ & 0.00 & $2.0 \%$ \\
$\mathbf{8}$ & 153 & 5.7 & 2.2 & 147 & 6.7 & 1.9 & $0.000 * * *$ & $-1.49,-0.55$ & 0.06 & $18.0 \%$ \\
$\mathbf{9}$ & 173 & 6.4 & 2.1 & 183 & 7.0 & 1.7 & $0.002 * *$ & $-1.01,-0.23$ & 0.03 & $9.6 \%$ \\
$\mathbf{1 0}$ & 144 & 7.0 & 1.6 & 130 & 7.1 & 1.7 & 0.634 & $-0.49,0.3$ & 0.00 & $1.4 \%$ \\
$\mathbf{1 1}$ & 144 & 6.7 & 1.8 & 121 & 6.9 & 1.9 & 0.620 & $-0.57,0.34$ & 0.00 & $1.7 \%$ \\
$\mathbf{1 2}$ & 97 & 6.5 & 2.0 & 77 & 6.9 & 2.0 & 0.192 & $-1.01,0.2$ & 0.01 & $6.2 \%$
\end{tabular}




\section{Discussion}

The aim of this study was to conduct a national FMS assessment, with a key focus on the maturation of FMS proficiency across the age span of primary school, while investigating FMS disparities between sex in Irish children. The findings from this research shows the dearth of proficiency across all FMS components throughout primary school, with the children showing $60.6 \%$ of MNM in balance skills, while just over half achieve MNM in the locomotor (52.8\%) and object control skills (54.8\%).

Examining the MNM of individual skills (Figure 1), skills such as slide (67\%), hop (68.4\%), run (75.3\%) and catch (73.5\%) show relatively high levels of MNM. This is expected, as it has been established that these skills can be mastered by eight years of age (Gallahue \& Ozmun, 2006). Armed with this knowledge, the low scores of the younger ages of five, six and even seven years of age can be expected as they have not reached their full maturation potential at this stage. As shown in Table 1 however, the older cohort also exhibit low scores and have not achieved MNM in any of the skills, with overhand throw (26.7\%), one handed strike (45.7\%), and two handed strike $(31.2 \%)$ scoring particularly low among 12 year olds. Similar levels of MNM are seen among the nine year old participants and their Australian counterparts (Cliff et al., 2012), with slide (81.7\%), underhand roll (37\%), stationary dribble (68.7\%), horizontal jump (50.1\%), and catch $(81.1 \%)$ all showing comparable results. It should be noted, the Australian children scored notably higher (Cliff et al., 2012) in skills such as two handed strike (28.2\%), kick (49.6\%), run (73.5\%), and overhand throw (12.4\%), with Irish children only surpassing them with the hop (68.2\%).

Looking at recent Irish findings (Kelly et al., 2018), one handed strike (28.6\%), horizontal jump (47\%), and catch (73.5\%) all show similar levels of MNM. In the same article, lower levels of MNM in several skills, such as run (42.7\% vs $75.3 \%)$, hop (27.5\% 
vs $68.4 \%)$, vertical jump (22.2\% vs $34 \%)$ and kick (37.9\% vs $49.8 \%)$. Conversely, the results presented here show lower proficiency in skills such as skip (69.4\%), gallop (19.8\%), stationary dribble (52.2\%) and overhand throw (16\%). The differences may be because of the inclusion of a wider age range (five to 12 years) and the large number of schools who participated in this study. Regardless of these differences, it is clear that Irish children are not mastering these basic skills (Bolger et al., 2018; Farmer et al., 2017; Kelly et al., 2018). Considering the Irish primary school PE curriculum places a heavy emphasis on movement skill development, it is particularly concerning that the level of MNM among the 12 year old participants is so low, specifically the object control skills. Higher skill proficiency has been reported in Irish adolescents (O’ Brien et al., 2016) in the overhand throw ( $83 \%$ vs $26.7 \%)$, two handed strike (92\%), stationary dribble $(86 \%$ vs $68.8 \%$ ), and kicking (98\% vs $69.8 \%$ ). Taking that some of the most popular extracurricular sports in Ireland are Gaelic football, soccer, hurling, and basketball (CSSPA, 2010), the assumption could be made that this lack of basic skill proficiency could be having a detrimental impact on physical activity participation rates. O’ Brien et al (2016) also report that just $23 \%$ of 12 to 13 year olds have MNM of the vertical jump, compared to the $45.9 \%$ MNM presented in this study's 12 year old participants. When one considers that the 11 year olds show greater proficiency (46.6\%) than their 12 year old counter parts, it is concerning to see that the already low levels of proficiency in the vertical jump seem to decline with age. This finding is reflected in previous research, with adolescents showing similarly low levels of FMS proficiency (Hardy et al., 2010; Okely \& Booth, 2004). This is alarming, as children who have not mastered the FMS are less likely to take part in PA due to a lack of basic movement skills (Barnett et al., 2009; Lubans et al., 2010; Okely et al., 2001). With recent findings showing high levels of screen time and increased sedentary behaviour amongst Irish children (Harrison et al., 2013), and only $12 \%$ of Irelands youth achieving the recommended one hour of PA a day (Woods et al., 2010), these low levels of FMS proficiency should come as no surprise. 
When comparing FMS proficiency across the primary school age-span (Figure 2), significant improvements in ability can be seen over time up to age ten. Increased proficiency as children get older is not surprising, as motor control typically develops as a child grows (Gallahue \& Ozmun, 2006), however it does not occur naturally and mastery of these skills must be learned, practiced and reinforced (Hamilton et al., 1999; Robinson \& Goodway, 2013). Considering this, one could expect to see significant developmental increases as the children progress through school, until mastery is achieved. As already shown (Table1), this is not the case, as there are low levels of mastery present across several skills, and only $56.7 \%$ of children achieve overall MNM by the age of 12 . It is interesting to note that the improvements in proficiency plateau at ten years of age, not just in the overall FMS, but the locomotor and balance subtests too. Only object control continues to significantly increase from ten to 11 years of age, and overall FMS actually declines from 11 to 12 years of age, along with all three subtests. Understanding why these skills are not improving as they progress through school could be crucial to engaging more Irish children in long term physical activity. Future research should seek to understand why these skills are not being acquired. A limitation of this study is not taking the nested nature of the data into account, and future work should look to calculate the total variability in FMS scores to show a more nuanced view of school and participant level, rather than the overview presented here.

A difference between sexes in FMS proficiency has been suggested in children (Barnett et al., 2009; Erwin \& Castelli, 2008; Goodway et al., 2013; Hardy et al., 2010), with previous Irish research showing boys scoring significantly higher in object control skills, and vice versa for girls in the locomotor skills (Bolger et al., 2018; Kelly et al., 2018). Looking at the overall FMS scores presented (Table 2) where significant differences between sex is only observed in 11 and 12 year olds, it would be easy to assume that there is no significant gap in Ireland. This assumption would be premature 
however, with girls scoring significantly higher in locomotor skills than boys at age; five, eight, nine and ten (Table 3). These findings should be taken with caution, however, as the effect sizes are small, with only a moderate effect size at age five. There are no significant differences between boys and girls for locomotor skills at age 11, but it is interesting to note that, while not significant, boys overtake girls in locomotor proficiency at the age of 12. Girls also scored higher than boys in the balance subtest at all ages (Table 4), scoring significantly higher at age; five, six, eight, and nine. Again, the effect sizes are small, with only age eight showing a moderate effect size.

Boys score significantly higher in object control skills (Table 5), with the exception of the five year old group, and corroborate Bolger et al. (2018) findings of Irish boys performing better in object control skills. While the boys participants significantly outscored the girls across most ages, it is interesting to note that the effect size increases in the older age groups, maintaining a moderate effect size across the ages of ten to 12 . This may represent a key turning point in girls object control development, as O' Brien et al. (2016) also shows female adolescents to have significantly less mastery of the object control skills. The CSSPA (2010) report shows $24 \%$ of Irish girls take part in dance compared to $4 \%$ of boys. This may explain why they develop their locomotor and balance skills faster. In contrast, the same report demonstrates that boys have a higher rate of extra-curricular sport participation in Ireland, predominantly made up of Gaelic games, soccer and rugby, all of which involve object control skills (CSSPA, 2010). A greater proficiency in object control skills has been suggested as a predictor of physical activity (Barnett et al., 2009). Given that the most popular sports in Ireland revolve around object control skills (CSSPA, 2010), it seems prudent to place an emphasis on these skills in primary school aged children, particularly with girls. An increased proficiency in these skills at a young age could see the perceived competence of the child increase, which can give them confidence to take part in sport in later life, thus creating a positive spiral of 
engagement from an early age (Stodden et al., 2012).

Regarding the positive association between childhood FMS proficiency and PA levels in later life (Stodden et al., 2008), this study could have important implications for the future health of children. The health benefits associated with PA are substantial (Dobbins et al., 2013), and several studies have shown an inverse relationship between FMS competency and weight status (Lubans et al., 2010). Given the current obesity crisis (World Health Organisation, 2015, Global trends in overweight an obesity) and what we know about the benefits of PA (Warburton et al., 2006), establishing FMS from an early developmental age should not be ignored. Interventions focusing on FMS development have been proven to be effective on numerous occasions (Hume et al., 2008; Okely \& Booth, 2004; van Beurden et al., 2003), but despite this, there is a dearth of research in FMS proficiency in Irish primary school children. The lack of skills mastery shown here, and in other studies, can further emphasise the need to prioritise FMS development in children. It seems obvious that without these fundamental skills, attaining a high level of proficiency in any sport becomes significantly more challenging (Stodden et al., 2008, 2012). In addition, the prevalence of withdrawal from physical activity participation is at its highest among teenagers (De Meester et al., 2009). Given the emerging evidence suggesting that developing FMS in children leads to less drop-outs in teenage years (Jaakkola \& Washington, 2013), it seems paramount that FMS development be placed at the heart of any programme when planning physical education or sports specific training for young children.

\section{Conclusion}

The results of this study highlight the low levels of FMS mastery, outlines the plateau in maturation of motor skill development in the Irish primary school cycle, and further supports the hypotheses of the proficiency disparity in FMS that exists among 
boys and girls. It is expected that the results presented here will help to establish FMS norms of primary school children, both in Ireland and further afield. Future research should seek to explore Irish children's physical activity levels, along with health-related fitness measures, and examine the relationship between FMS and the afore mentioned components to expand on the hypotheses outlined in this paper in an Irish context, and further understand what motivates children to participate in physical activity. 


\section{References}

Barela, J. A. (2013). Fundamental motor skill proficiency is necessary for children's motor activity inclusion. Motriz: Revista de Educação Física, 19(3), 548-551. https://doi.org/10.1590/S1980-65742013000300003

Barnett, L. M., van Beurden, E., Morgan, P. J., Brooks, L. O., \& Beard, J. R. (2009). Childhood Motor Skill Proficiency as a Predictor of Adolescent Physical Activity. Journal of Adolescent Health, 44(3), 252-259. https://doi.org/10.1016/j.jadohealth.2008.07.004

Belton, S., O’ Brien, W., Meegan, S., Woods, C., \& Issartel, J. (2014). Youth-Physical Activity Towards Health: evidence and background to the development of the YPATH physical activity intervention for adolescents. BMC Public Health (2014) 14(1), 14(1). https://doi.org/10.1186/1471-2458-14-122

Beurden, E. Van, Zask, A. I., I, L. M. B., \& I, U. C. D. (2002). Fundamental movement skills - How do primary school children perform? The 'Move it Groove it' program in rural Australia. Journal of Sceince and Medicine, 5(3) 244-252. https://doi.org/10.1016/S1440-2440(02)80010-X

Bolger, L. E., Bolger, L. A., O’ Neill, C., Coughlan, E., O’Brien, W., Lacey, S., \& Burns, C. (2018). Age and Sex Differences in Fundamental Movement Skills Among a Cohort of Irish School Children. Journal of Motor Learning and Development, 6(1), 81-100.

https://doi.org/10.1123/jmld.2017-0003

Booth, M. L., Okely, A. D., McLellan, L., Phongsavan, P., Macaskill, P., Patterson, J., ... Holland, B. (1999). Mastery of fundamental motor skills among New South Wales school students: prevalence and sociodemographic distribution. Journal of 
Science and Medicine in Sport / Sports Medicine Australia, 2(2), 93-105.

https://doi.org/10.1086/590667

Bruininks, R. H. (2005). Bruininks-Oseretsky test of motor proficiency. Circle Pines, MN: AGS Publishing.

Cavalheri, V., Straker, L., Gucciardi, D. F., Gardiner, P. A., \& Hill, K. (2016).

Changing physical activity and sedentary behaviour in people with COPD. Respirology, 21(3), 419-426.

https://doi.org/10.1111/resp.12680

Clark, J. E. (2007). On the Problem of Motor Skill Development. Journal of Physical Education, Recreation \& Dance, 78(5), 39-44.

https://doi.org/10.1080/07303084.2007.10598023

Cliff, D. P., Okely, A. D., Morgan, P. J., Jones, R. A., Steele, J. R., \& Baur, L. A. (2012). Proficiency Deficiency: Mastery of Fundamental Movement Skills and Skill Components in Overweight and Obese Children. Obesity, 20(5), 1024-1033. https://doi.org/10.1038/oby.2011.241

Cliff, D. P., Okely, A. D., Smith, L. M., \& McKeen, K. (2009). Relationships between Fundamental Movement Skills and Objectively Measured Physical Activity in Preschool Children. Pediatric Exercise Science, 21(4), 436-449. https://doi.org/10.1123/pes.21.4.436

Cohen, J. (1988). Set Correlation and Contingency Tables. Applied Psychological Measurement, 12(4), 425-434. https://doi.org/10.1177/014662168801200410

Colley, R. C., Carson, V., Garriguet, D., Janssen, I., Roberts, K. C., \& Tremblay, M. S. (2017). Statistics Canada, Catalogue no. 82-003-X Physical activity of Canadian children and youth. Health Reports (Vol. 28). Retrieved from 
https://search.proquest.com/openview/2a9ae10ae66545f7253dea0e2141fab5/1?cbl $=46838 \&$ pq-origsite $=$ gscholar

Cools, W., Martelaer, K. De, Samaey, C., \& Andries, C. (2009). Movement skill assessment of typically developing preschool children: a review of seven movement skill assessment tools. Journal of Sports Science \& Medicine, 8(2), $154-168$.

https://doi.org/10.1016/S0031-9406(05)66164-0

De Meester, F., van Lenthe, F. J., Spittaels, H., Lien, N., \& De Bourdeaudhuij, I. (2009). Interventions for promoting physical activity among European teenagers: a systematic review. International Journal of Behavioral Nutrition and Physical Activity, 6(1), 82 .

https://doi.org/10.1186/1479-5868-6-82

Deitz, J. C., Kartin, D., \& Kopp, K. (2009). Review of the Bruininks-Oseretsky Test of Motor Proficiency, Second Edition (BOT-2). https://doi.org/10.1080/J006v27n04_06

Department of Education, I. G. (1999). Physical Education Primary School Curriculum Curaclam na Bunscoile. Retrieved from https://www.curriculumonline.ie/getmedia/ca8a385c-5455-42b6-9f1c88390be91afc/PSEC05_Physical-Education_Curriculum.pdf

Dobbins M, Husson H, Decorby K, \& R1, L. (2013). School-based physical activity programs for promoting physical activity and fitness in children and adolescents aged 6 to 18 (Review). Cochrane database of systematic reviews (2) https://doi.org/10.1002/14651858.CD007651.pub2

Eime, R. M., Young, J. A., Harvey, J. T., Charity, M. J., \& Payne, W. R. (2013). A systematic review of the psychological and social benefits of participation in sport 
for children and adolescents: informing development of a conceptual model of health through sport. International Journal of Behavioral Nutrition and Physical Activity, 10(1), 98 .

https://doi.org/10.1186/1479-5868-10-98

Erwin, H. E., \& Castelli, D. M. (2008). National Physical Education Standards: A Summary of Student Performance and Its Correlates. Research Quarterly for Exercise and Sport 79(4), 495-505

https://doi.org/10.1080/02701367.2008.10599516

Farmer, O., Belton, S., O’Brien, W., Farmer, O., Belton, S., \& O’Brien, W. (2017). The Relationship between Actual Fundamental Motor Skill Proficiency, Perceived Motor Skill Confidence and Competence, and Physical Activity in 8-12-Year-Old Irish Female Youth. Sports, 5(4), 74. https://doi.org/10.3390/sports5040074

Fransen, J., D’hondt, E., Bourgois, J., Vaeyens, R., Philippaerts, R. M., \& Lenoir, M. (2014). Motor competence assessment in children: Convergent and discriminant validity between the BOT-2 Short Form and KTK testing batteries. Research in Developmental Disabilities, 35, 1375-1383. https://doi.org/10.1016/j.ridd.2014.03.011

Fundamental Motor Skills: A Manual for Classroom Teachers. (1996). State of Victoria.

Gallahue, D. L., \& Ozmun, J. C. (2006). Understanding motor development : infants, children, adolescents, adults. Boston: McGraw Hill.

Retrieved from https://books.google.ie/books/about/Understanding_Motor_Development.html?id= eNDwPgAACAAJ\&redir_esc $=\mathrm{y}$ 
Gallahue, D., Ozmun, J., \& Goodway, J. (2006). Understanding motor development: Infants, children, adolescents, adults. Boston: McGraw Hill.

Retrieved from

https://scholar.google.com/scholar?hl=en\&as_sdt=0\%2C5\&q=understanding + mot or + development + gallahue + ozmun $+\&$ btnG $=$

Goodway, J. D., Robinson, L. E., \& Crowe, H. (2013). Gender Differences in Fundamental Motor Skill Development in Disadvantaged Preschoolers From Two Geographical Regions. Research Quarterly for Exercise and Sport 81(1), 17-24 https://doi.org/10.1080/02701367.2010.10599624

Hamilton, M. L., Goodway, J., \& Haubenstricker, J. (1999). Parent-Assisted Instruction in a Motor Skill Program for At-Risk Preschool Children. Adapted Physical Activity Quarterly, (16), 415-426.

Retrieved from https://www.researchgate.net/publication/281275675

Hardy, L. L., Barnett, L., Espinel, P., \& Okely, A. D. (2013). Thirteen-year trends in child and adolescent fundamental movement skills: 1997-2010. Medicine and Science in Sports and Exercise, 45(10), 1965-1970.

https://doi.org/10.1249/MSS.0b013e318295a9fc

Hardy, L. L., King, L., Farrell, L., Macniven, R., \& Howlett, S. (2010). Fundamental movement skills among Australian preschool children. Journal of Science and Medicine in Sport, 13(5), 503-508.

https://doi.org/10.1016/J.JSAMS.2009.05.010

Harrison, M., Murphy, N. M., Lane, A., \& Murphy, N. (2013). Screen Time Increases Risk of Overweight and Obesity in Active and Inactive 9-Year-Old Irish Children: A Cross Sectional Analysis. Article in Journal of Physical Activity and Health, 11, 985-991. 
https://doi.org/10.1123/jpah.2012-0182

Hume, C., Okely, A., Bagley, S., Telford, A., Booth, M., Crawford, D., \& Salmon, J. (2008). Does Weight Status Influence Associations Between Children's Fundamental Movement Skills and Physical Activity? Research Quarterly for Exercise and Sport 79(2), 158-165.

https://doi.org/10.1080/02701367.2008.10599479

Jaakkola, T., Yli-Piipari, S., Huotari, P., Watt, A., \& Liukkonen, J. (2016). Fundamental movement skills and physical fitness as predictors of physical activity: A 6-year follow-up study. Scandinavian Journal of Medicine \& Science in Sports, 26(1), $74-81$.

https://doi.org/10.1111/sms.12407

Jaakkola, Timo, \& Washington, T. (2013). The relationship between fundamental movement skills and self-reported physical activity during Finnish junior high school. Physical Education \& Sport Pedagogy, 18(5), 492-505.

https://doi.org/10.1080/17408989.2012.690386

Junior, K., Patrick, S., Nagle Junior, N., Thomas Senior, S., An Eiscir Riada, G., \& Offaly, C. (2005). DEIS (Delivering Equality Of Opportunity In Schools) An Action Plan for Educational Inclusion. Retrieved from https://www.education.ie/en/Publications/PolicyReports/deis_action_plan_on_educational_inclusion.pdf Katzmarzyk, P. T., \& Staiano, A. E. (2017). Relationship Between Meeting 24-Hour Movement Guidelines and Cardiometabolic Risk Factors in Children. Journal of Physical Activity and Health, 14(10), 779-784.

https://doi.org/10.1123/jpah.2017-0090

Kelly, L., O’Connor, S., Harrison, A. J., \& Ní Chéilleachair, N. J. (2018). Does 
fundamental movement skill proficiency vary by sex, class group or weight status? Evidence from an Irish primary school setting. Journal of Sports Sciences, 1-9. https://doi.org/10.1080/02640414.2018.1543833

LeGear, M., Greyling, L., Sloan, E., Bell, R. I., Williams, B.-L., Naylor, P.-J., \& Temple, V. A. (2012). A window of opportunity? Motor skills and perceptions of competence of children in Kindergarten. International Journal of Behavioral Nutrition and Physical Activity, 9(1), 29. https://doi.org/10.1186/1479-5868-9-29

Logan, S. W., Ross, S. M., Chee, K., Stodden, D. F., \& Robinson, L. E. (2018). Fundamental motor skills: A systematic review of terminology. Journal of Sports Sciences. 36(7), 781-796 https://doi.org/10.1080/02640414.2017.1340660

Lubans, D. R., Morgan, P. J., Cliff, D. P., Barnett, L. M., \& Okely, A. D. (2010). Fundamental movement skills in children and adolescents. Review of associated health benefits. Sport Medicine, 40(12), 1019-1035. https://doi.org/10.2165/11536850-000000000-00000

Metcalfe, J., \& Clark, J. E. (2002). The mountain of motor development: A metaphor Developmental Coordination Disorder View project LD and motor competency Motor Development: Research and reviews 2, 163-190.

Retrieved from https://www.researchgate.net/publication/273403393

Mukherjee, S., Ting Jamie, L. C., \& Fong, L. H. (2017). Fundamental Motor Skill Proficiency of 6- to 9-Year-Old Singaporean Children. Perceptual and Motor Skills, 124(3), 584-600.

https://doi.org/10.1177/0031512517703005

O’ Brien, W., Belton, S., \& Issartel, J. (2016). Fundamental movement skill proficiency 
amongst adolescent youth. Physical Education and Sport Pedagogy. 21(6), 557571

https://doi.org/10.1080/17408989.2015.1017451

Office of Disease Prevention and Health Promotion, U. G. (2018). 2018 Physical Activity Guidelines Advisory Committee Scientific Report. Retrieved from https:/health.gov/paguidelines/secondedition/report/pdf/PAG_Advisory_Committee_Report.pdf

Okely, A. ., Booth, M. ., \& Patterson, J. . (2001). Relationship of physical activity to fundamental movement skills among adolescents. Medicine and Science in Sports and Exercise, 33(11), 1899-1904.

https://doi.org/10.1097/00005768-200111000-00015

Okely, A. D., \& Booth, M. L. (2004). Mastery of fundamental movement skills among children in New South Wales: Prevalence and sociodemographic distribution. Journal of Science and Medicine in Sport, 7(3), 358-372. https://doi.org/10.1016/S1440-2440(04)80031-8

Robinson, L. E., \& Goodway, J. D. (2013). Instructional Climates in Preschool Children Who Are At-Risk. Part I. Research Quarterly for Exercise and Sport 80(3), 533542.

https://doi.org/10.1080/02701367.2009.10599591

Robinson, L. E., Logan, S. W., Kipling Webster, E., Getchell, N., \& Pfeiffer, K. A. (2015). Relationship Between Fundamental Motor Skill Competence and Physical Activity During Childhood and Adolescence: A Systematic Review. Kinesiology Review, 4, 416-426.

https://doi.org/10.1123/kr.2013-0012

Robinson, L. E., Stodden, D. F., Barnett, L. M., Lopes, V. P., Logan, S. W., Rodrigues, 
L. P., \& D’Hondt, E. (2015). Motor Competence and its Effect on Positive

Developmental Trajectories of Health. Sports Medicine, 45(9), 1273-1284. https://doi.org/10.1007/s40279-015-0351-6

Rudd, J. R., Barnett, L. M., Butson, M. L., Farrow, D., Berry, J., \& Polman, R. C. J. (2015). Fundamental Movement Skills Are More than Run, Throw and Catch: The Role of Stability Skills. PloS one 10(10), e0140224 https://doi.org/10.1371/journal.pone.0140224

Stodden, D. F., Goodway, J. D., Langendorfer, S. J., Roberton, M. A., Rudisill, M. E., Garcia, C., \& Garcia, L. E. (2008). A Developmental Perspective on the Role of Motor Skill Competence in Physical Activity: An Emergent Relationship. Quest, 60(2), 290-306.

https://doi.org/10.1080/00336297.2008.10483582

Stodden, D. F., Goodway, J. D., Stephen, J., Roberton, M. A., Rudisill, M. E., Garcia, C., \& Garcia, L. E. (2012). A Developmental Perspective on the Role of Motor Skill Competence in Physical Activity : An Emergent Relationship. Motor Competence and Physical Activity, (February 2013), 37-41.

https://doi.org/10.1080/00336297.2008.10483582

Temple, V. A., \& Foley, J. T. (2017). A Peek at the Developmental Validity of the Test of Gross Motor Development...: EBSCOhost. Journal of Motor Learning and Development, 5, 5-14. Retrieved from http://web.b.ebscohost.com.dcu.idm.oclc.org/ehost/pdfviewer/pdfviewer?vid=1\&si $\mathrm{d}=7 \mathrm{de} 1 \mathrm{ac} 3 \mathrm{~d}-003 \mathrm{e}-418 \mathrm{f}-\mathrm{a} 78 \mathrm{~b}-43 \mathrm{c} 3 \mathrm{a} 9708 \mathrm{a} 95 \%$ 40sessionmgr102

Ulrich, D. (2013). The Test of Gross Motor Development-3 (TGMD-3): Administration, Scoring, \& International Norms. Spor Bilimeri Dergisi 24(2) 27-33 Retrieved from http://dergipark.gov.tr/download/article-file/151209\#page=35 
Van Beurden, E., Barnett, L. M., Zask, A., Dietrich, U. C., Brooks, L. O., \& Beard, J. (2003). Can we skill and activate children through primary school physical education lessons? "Move it Groove it" - A collaborative health promotion intervention. Preventive Medicine, 36(4), 493-501. https://doi.org/10.1016/S0091-7435(02)00044-0

Warburton, D. E. R., Nicol, C. W., \& Bredin, S. S. D. (2006). Health benefits of physical activity: the evidence. CMAJ : Canadian Medical Association Journal = Journal de l'Association Medicale Canadienne, 174(6), 801-809. https://doi.org/10.1503/cmaj.051351

Woods, C., Moyna, N., \& Quinlan, A. (2010). The Children's Sport Participation and Physical Activity Study (CSPPA Study). The Irish Sports Council.

Yee, K., Wong, A., \& Cheung, S. Y. (2010). Confirmatory Factor Analysis of the Test of Gross Motor Development-2. Measurement in Physical Education and Exercise Science, 14, 202-209.

https://doi.org/10.1080/10913671003726968

Yun, J., \& Ulrich, D. A. (2002). Estimating Measurement Validity: A Tutorial. Adapted Physical Activity Quarterly, 19(1), 32-47.

https://doi.org/10.1123/apaq.19.1.32 